\title{
Temperatura base e filocrono em duas cultivares de oliveira
}

\author{
Base temperature and phyllochron in two olive cultivars
}

\author{
Fabrina Bolzan Martins ${ }^{\mathrm{I}}$ Diogo da Fonseca Reis ${ }^{\mathrm{II}}$ Marcos Vinícius Marques Pinheiro ${ }^{\mathrm{III}}$
}

RESUMO

\begin{abstract}
O objetivo deste trabalho foi estimar a temperatura base para emissão de folhas e determinar o filocrono em duas cultivares de oliveira, 'Arbequina' e 'MGS ASC315', durante a fase de muda em condições de campo. Foi instalado um experimento na Fazenda Experimental da Empresa de Pesquisa Agropecuária de Minas Gerais, Maria da Fé, MG. Utilizou-se o delineamento inteiramente casualizado, em esquema fatorial $2 \times 6$, sendo duas cultivares e seis épocas de transplantio, com quinze repetições. A temperatura base (Tb) foi estimada usando a metodologia do menor valor do quadrado médio do erro (QME), e o filocrono foi obtido através do inverso do coeficiente angular da regressão linear entre o número de folhas emitidas e a soma térmica acumulada. A Tb estimada para a Arbequina foi de $10,5^{\circ} \mathrm{C}$ e $11^{\circ} \mathrm{C}$ para a MGS ASC315. O filocrono diferiu estatisticamente somente entre as cultivares, sendo menor para a 'Arbequina' $\left(21,7^{\circ} \mathrm{C}\right.$ dia $^{-1}$ folha $\left.^{-1}\right)$ quando comparada com a 'MGS ASC315' (41,6 ${ }^{\circ} \mathrm{C}$ dia $^{-1}$ folha $\left.{ }^{-1}\right)$.
\end{abstract}

Palavras-chave: Olea europaea, fenologia, temperatura do ar.

\section{ABSTRACT}

The objective of this work was to estimate the base temperature for leaf appearance and the phyllochron for two cultivars of Olea europaea L. A field experiment was carried out in the experimental area of the Agricultural Research Corporation of Minas Gerais, Maria da Fé, MG. The experimental design was completely randomized with two cultivars and six planting dates. Base temperature (Tb) was estimated by the minimum mean square error (MSE) and the phyllochron was estimated by the inverse of the slope of regression between main stem leaf number and accumulated thermal time. The estimated base temperature was $10.5^{\circ} \mathrm{C}$ for Arbequina and $11^{\circ} \mathrm{C}$ for MGS ASC315. The phyllochron was statistically different only between cultivars, lower for 'Arbequina' $\left(21.7^{\circ} \mathrm{C}\right.$ day ${ }^{-1}$ leaf $\left.{ }^{1}\right)$ compared to 'MGS ASC315' (41.6 ${ }^{\circ} \mathrm{C}$ day $^{-1}$ leaf $\left.^{1}\right)$.

Key words: Olea europaea, phenology, air temperature.

\section{INTRODUÇÃO}

A espécie Olea europaea L., popular oliveira, é uma árvore frutífera subtropical de grande longevidade, sendo uma das mais cultivadas na região do Mediterrâneo (DENNEY et al., 1985). A espécie possui importância no cenário econômico mundial por fazer parte da dieta alimentar de muitos países, além de ser rica em antioxidantes com funções-chave na diminuição do risco de doenças cardiovasculares (GOULAS et al., 2009).

No Brasil não existem áreas destinadas ao plantio de oliveira em escala comercial. Porém, como o Brasil importa cerca de 64,5 mil toneladas de produtos oriundos da oliveira (IOC, 2012), o seu cultivo, apesar de recente, está em expansão (VIEIRA NETO et al., 2011), principalmente nas regiões sul e sudeste do país. Para tornar realidade a expansão desta atividade no Brasil, é necessário conhecer os aspectos básicos que norteiam o desenvolvimento da oliveira, além de conhecer a adaptabilidade da oliveira em regiões fora

'Instituto de Recursos Naturais (IRN), Universidade Federal de Itajubá (UNIFEI), 37500-903, Itajubá, MG, Brasil. E-mail: fabrinabm@gmail.com. Autor para correspondência.

"Curso de Engenharia Ambiental, UNIFEI, Itajubá, MG, Brasil.

IIIPrograma de Pós-graduação em Botânica, Departamento de Biologia Vegetal, Universidade Federal de Viçosa (UFV), Viçosa, MG, Brasil. 
do seu centro de origem. Nesse sentido, vários fatores ambientais são considerados, e no caso específico da oliveira, a temperatura do ar é considerada o maior motivo de preocupação (DENNEY et al., 1985), pois é o principal elemento meteorológico que afeta o desenvolvimento (vegetativo e reprodutivo) da maioria das espécies vegetais (STRECK et al., 2004; PÉREZLOPEZ et al., 2008), incluindo a oliveira (DENNEY et al., 1985; AYERZA \& SIBBETT, 2001). O conhecimento das necessidades térmicas do desenvolvimento vegetativo, como: emissão de folhas, e do desenvolvimento reprodutivo, como: inflorescência, florescimento, frutificação e maturação (SANZCORTÉZ et al., 2002), é vital para otimizar as estratégias de manejo e escolher as cultivares mais adaptadas as condições climáticas de cultivo (PÉREZ-LOPEZ, 2008).

Uma forma bastante usual de quantificar a temperatura do ar no tempo vegetal é através da soma térmica, cuja unidade é dada em graus dias $\left({ }^{\circ} \mathrm{C} \mathrm{dia}{ }^{-1}\right)$ (ROSA et al., 2009). Existem muitos métodos de cálculo da soma térmica, no método mais simples, são acumulados os valores de temperatura média diária do ar acima de uma temperatura base ( $\mathrm{Tb}$ ), a qual é considerada a temperatura abaixo da qual o desenvolvimento é nulo ou desprezível (ARNOLD, 1960; McMASTER \& WILHELM, 1997; MARTINS et al., 2007).

Para quantificar o desenvolvimento, geralmente utiliza-se a variável número de folhas acumuladas (NF), por esta variável estar associada com o aumento da área foliar, interceptação da radiação solar e fotossíntese (XUE et al., 2004; ROSA et al., 2009).

Uma maneira utilizada como forma de relacionar a soma térmica e o NF é através do conceito de filocrono, que é o intervalo contabilizado para o aparecimento de duas folhas consecutivas na haste principal (XUE et al., 2004; STRECK et al., 2005), tendo como unidade ${ }^{\circ} \mathrm{C}$ dia $^{-1}$ folha $^{-1}$ (STRECK et al., 2004; MARTINS et al., 2007). O filocrono é obtido através da regressão linear entre NF e a soma térmica acumulada (STa).

Vários estudos foram realizados utilizando o conceito do filocrono em muitas culturas agrícolas anuais como: trigo (XUE et al., 2004; ROSA et al., 2009), cártamo (STRECK et al., 2005), tomate (PIVETTA et al., 2007), berinjela (MALDANER et al., 2009), milho (STRECK et al., 2009); para culturas perenes, como: laranja (VOLPE, et al., 2002), eucalipto (MARTINS et al., 2007) e araucária (ASSUMPÇÃO NETO, 2008); e culturas utilizadas para fins ornamentais e medicinais como o lírio (STRECK et al., 2004) e calêndula (KOEFENDER et al., 2008). No entanto, não existem registros bibliográficos da determinação do filocrono, assim como, da Tb para emissão de folhas em nenhuma cultivar de oliveira, consistindo o incentivo para a realização desse trabalho. Estudos básicos dessa natureza podem ser importantes para avaliar a adaptabilidade térmica em ambientes fora do centro de origem da espécie (MELO-ABREU et al., 2004), além de ser útil no manejo para melhorar a qualidade da muda (MARTINS et al., 2007), como também na implantação e estabelecimento da oliveira à campo.

O objetivo deste trabalho foi estimar a temperatura base para emissão de folhas e determinar o filocrono em duas cultivares de oliveira, 'Arbequina' e 'MGS ASC315', durante a sua fase de muda em condições de campo.

\section{MATERIAL E MÉTODOS}

O experimento foi instalado à campo na área experimental da Empresa Agropecuária de Minas Gerais (EPAMIG), Maria da Fé, Minas Gerais (latitude: 22¹8'29' S; longitude: 45²2'31' 'W; e altitude: $1.276 \mathrm{~m}$ ). O clima do local, segundo a classificação de Köppen, é Cwb, subtropical de altitude com invernos secos e verões chuvosos de temperaturas brandas (VIEIRA NETO et al., 2011).

Foram utilizadas mudas de duas cultivares de oliveira provenientes do enraizamento de estacas semilenhosas e ausentes de brotações. Utilizou-se a estaquia como método de propagação, ao invés de sementes, principalmente, devido ao lento processo de germinação das sementes de oliveira (ACEBEDO et al., 1997). As duas cultivares utilizadas foram: 'Arbequina', destinada à produção de azeite, e 'MGS ASC315' (conhecida antigamente por Ascolano), destinada à produção de azeitona (VIEIRA NETO et al., 2011).

O delineamento utilizado foi o inteiramente casualizado, organizado em esquema fatorial $2 \times 6$, sendo duas cultivares e seis épocas de transplantio, com quinze repetições por tratamento. A unidade experimental foi constituída de uma estaca semilenhosa enraizada de oliveira, sendo plantada em vaso de polietileno de aproximadamente $4 \mathrm{~L}$, preenchidos com substrato constituído de terra e composto orgânico comercial (Provaso ${ }^{\circledR}$ ). Cada $\mathrm{m}^{3}$ de substrato foi enriquecido com $5 \mathrm{~kg}$ de superfosfato simples (18dag $\mathrm{kg}^{-1}$ de $\mathrm{P}_{2} \mathrm{O}_{5}$ ), $1 \mathrm{~kg}$ de cloreto de potássio (58dag $\mathrm{kg}^{-1}$ de $\mathrm{K}_{2} \mathrm{O}$ ) e 2,5kg de calcário dolomítico (PRNT 100\%). Os vasos foram envolvidos com papel jornal a fim de minimizar a absorção da radiação solar e assim, evitar o aumento de temperatura do substrato, que poderia ser uma fonte de erro experimental (MARTINS et al., 2007). O espaçamento utilizado entre os vasos foi de $20 \mathrm{~cm}$. Realizou-se irrigações regulares para minimizar o estresse hídrico nas plantas. 
Foram instaladas seis épocas de transplantio em intervalos de aproximadamente 30 dias, para que as plantas ficassem expostas a diferentes condições meteorológicas durante o seu desenvolvimento (ROSA et al., 2009). A data de instalação época 1 (E1) foi 20/05/2010, da época 2 (E2) foi 20/06/2010, da época 3 (E3) foi 20/07/2010, da época 4 (E4) foi 20/08/2010, da época 5 (E5) foi 29/09/2010 e da época 6 (E6) foi 27/10/2010. As épocas 1, 2, 3 e 4 foram utilizadas para estimar a $\mathrm{Tb}$, pois nessas épocas ocorreram as menores temperaturas do ar. Já as épocas 5 e 6 foram utilizadas para estimar o filocrono, pois o período de duração dessas épocas compreendeu a estação chuvosa da região, sendo preferencial para plantio de oliveira à campo.

O NF foi contado uma vez por semana. Para a sua contagem, a haste principal (primeira brotação) recebeu um anel colorido e a contagem foi iniciada quando havia uma folha visível. Considerou-se como folha visível aquela com, no mínimo, $1,0 \mathrm{~cm}$ de comprimento e coloração acinzentada (SANZ-CORTÉS et al., 2002). Finalizou-se a fase de muda quando cada repetição atingiu, no mínimo, 20 folhas visíveis (MARTINS et al., 2007).

Os dados diários de temperatura mínima e máxima do ar foram obtidos de uma estação meteorológica convencional pertencente ao Instituto Mineiro de Gestão das Águas (IGAM) e localizada na EPAMIG à, aproximadamente, $100 \mathrm{~m}$ do local de instalação do experimento.

Para o cálculo da soma térmica utilizouse o método proposto por ARNOLD (1960): $S T d=\frac{T M+T m}{2}-T b .1$ dia (Equação 1$)$ em que:

STd = soma térmica diária $\left({ }^{\circ} \mathrm{C} \mathrm{dia}{ }^{-1}\right), \mathrm{TM}=$ temperatura máxima diária do $\operatorname{ar}\left({ }^{\circ} \mathrm{C}\right), \mathrm{Tm}=$ temperatura mínima diária do $\operatorname{ar}\left({ }^{\circ} \mathrm{C}\right)$ e $\mathrm{Tb}=$ temperatura base da cultivar $\left({ }^{\circ} \mathrm{C}\right)$.

Para o cálculo da STa, acumulou-se a STd a partir da data de transplantio de cada época.

A partir dos dados do NF, foi estimada a Tb, conforme a metodologia do menor valor do quadrado médio do erro (QME) (SINCLAIR et al., 2004; MARTINS et al., 2007; LUCAS et al., 2012). Na metodologia do QME, foram ajustadas várias equações de regressão linear simples entre o NF (média do NF das 15 repetições de cada cultivar) e a STa para cada época de transplantio. Para o cálculo da STd, utilizou-se uma série de $\mathrm{Tb}$ variando de $0^{\circ} \mathrm{C}$ à $16^{\circ} \mathrm{C}$, com incrementos de $0,5^{\circ} \mathrm{C}$. $\mathrm{O}$ valor de $\mathrm{Tb}$, em cada época de transplantio, foi aquele que apresentou o menor valor do QME das regressões lineares. Já o valor da Tb para cada cultivar de oliveira foi obtido pela média aritmética dos valores de $\mathrm{Tb}$ encontrados em cada época de transplantio (MARTINS et al., 2007).

Com o valor de Tb obtido para cada cultivar de oliveira, foi estimado o valor do filocrono. Para isso, foram ajustadas equações de regressão linear simples entre o NF e a STa em cada unidade experimental da E5 e E6. O filocrono foi obtido pelo inverso do coeficiente angular da regressão linear (XUE et al., 2004). O filocrono das duas cultivares de oliveira (E5 e E6) foram submetidos à análise de variância pelo teste F, seguida de comparação de médias pelo teste Scott Knott, a 5\% de probabilidade.

\section{RESULTADOS E DISCUSSÃO}

Durante as seis épocas de transplantio no campo houve grande variação das condições meteorológicas, as quais foram importantes na estimativa da temperatura base e na obtenção do filocrono para as duas cultivares de oliveira. As temperaturas absolutas do ar oscilaram entre $-1,3^{\circ} \mathrm{C}$ e $31,4^{\circ} \mathrm{C}$, e ocorreram durante as épocas 4 e 6 , respectivamente. Durante as épocas 1 à 4, utilizadas na estimativa da Tb, a média da temperatura mínima do ar foi de $8,9^{\circ} \mathrm{C}$ e a média da temperatura máxima do ar foi de $24,3^{\circ} \mathrm{C}$. Nas épocas 5 e 6 , utilizadas para obtenção do filocrono, a média da temperatura mínima do ar foi de $13,7^{\circ} \mathrm{C}$ e a média da temperatura máxima foi de $26,3^{\circ} \mathrm{C}$.

Na estimativa da Tb da Arbequina, todas regressões entre NF e STa, apresentaram valores de coeficiente de regressão $\left(R^{2}\right)$ variando entre 0,7710 e 0,9839, para as épocas 1 e 4, respectivamente. Além disso, todos os coeficientes angulares e lineares foram significativos $(\mathrm{P}<0,05)$. Para a MGS ASC315, os valores de $\mathrm{R}^{2}$ de todas as unidades experimentais variaram entre 0,7920 (E1) e 0,9937 (E4), e os coeficientes angulares e lineares também foram significativos. Esses resultados demonstram que há relação linear entre as variáveis analisadas, o que confirma que a temperatura do ar é o principal elemento meteorológico que afeta o desenvolvimento das duas cultivares de oliveira, assim como ocorre em eucalipto (MARTINS et al., 2007); tomate (PIVETTA et al., 2007); melancia (LUCAS et al., 2012); berinjela (MALDANER et al., 2009); e outras culturas.

Houve variação entre os valores de $\mathrm{Tb}$ encontrados em cada época de transplantio em ambas cultivares. Para Arbequina, o menor valor do QME na E1 $(9,1048)$ foi para a Tb de $4,0^{\circ} \mathrm{C}$; na E2 o menor QME $(2,3571)$ foi para a $\mathrm{Tb}$ de $13,5^{\circ} \mathrm{C}$; na E3 o menor QME $(1,5544)$ foi para $\mathrm{Tb}$ de $10,5^{\circ} \mathrm{C}$; e para a $\mathrm{E} 4$ o menor QME $(1,6310)$ foi para a $\mathrm{Tb}$ de $14^{\circ} \mathrm{C}$ (Figura 1a). O valor assumido para a $\mathrm{Tb}$ da Arbequina foi de $10,5^{\circ} \mathrm{C}$, obtido através da média aritmética entre as $\mathrm{Tb}$ encontradas 

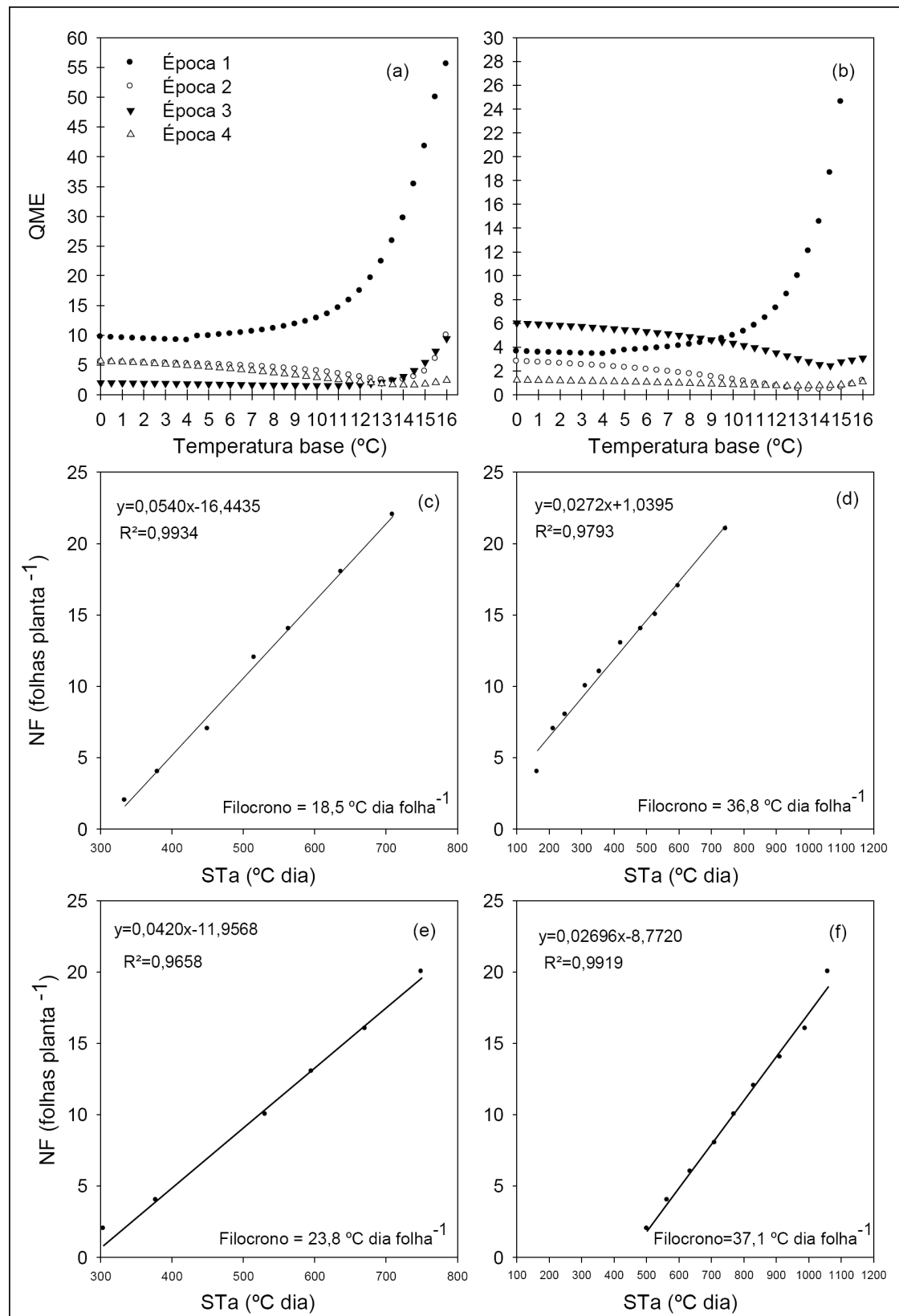

Figura 1 - Quadrado médio do erro (QME) da regressão linear entre número de folhas emitidas (NF) e soma térmica acumulada (STa) utilizando-se diferentes temperaturas base (Tb) para Arbequina (a) e MGS ASC315 (b) e Regressão linear entre NF e a STa utilizada para a estimativa do filocrono em mudas de Arbequina (c, e) e MGS ASC315 (d, f). Os painéis c, e referem-se a E5 e os painéis d, f referem-se a E6. Os painéis c, d, e, f são representativos de uma repetição. Maria da Fé, MG, 2010/2011.

em cada época de transplantio (E1 à E4). No presente trabalho, o valor de $\mathrm{Tb}=10,5^{\circ} \mathrm{C}$ assumido para Arbequina é superior aos encontrados para inflorescência $\left(5^{\circ} \mathrm{C}\right.$ ) (MORIONDO et al., 2001) e para o processo de quebra de dormência $\left(8,5^{\circ} \mathrm{C}\right.$ e $\left.8,8^{\circ} \mathrm{C}\right)$, em diferentes cultivares de oliveira na Itália e Espanha (MELO-ABREU et al., 2004). Além disso, foi similar aos valores encontrados para o florescimento de diferentes cultivares de oliveira na Espanha (ALCALÁ \& BARRANCO, 1992) (entre 10 à $13^{\circ} \mathrm{C}$ ). DENNEY et al. 
(1985) e AYERZA \& SIBBETT (2001) encontraram valores entre $0^{\circ} \mathrm{C} \mathrm{e} 4,5^{\circ} \mathrm{C}$ para o processo de vernalização em várias cultivares de oliveira no Texas, e alguns lugares da Argentina, Espanha, Itália, Peru e México.

Para MGS ASC315 os valores do QME variaram entre 0,4103 (E2) à 47,6393 (E1). Na E1, o menor QME $(3,3965)$ foi para a $\mathrm{Tb}$ de $4,0^{\circ} \mathrm{C}$; na E2 $(0,4103)$ foi para a Tb de $14^{\circ} \mathrm{C}$; na $\mathrm{E} 3(1,5485)$ para a $\mathrm{Tb}$ de $14,5^{\circ} \mathrm{C}$; e na E4 $(0,7265)$ para a Tb de $12,5^{\circ} \mathrm{C}$ (Figura $\left.1 \mathrm{~b}\right)$. O valor de Tb assumido para a MGS ASC 315 foi de $11^{\circ} \mathrm{C}$, sendo inferior a $\mathrm{Tb}$ de 13 e $14^{\circ} \mathrm{C}$ para a brotação foliar e crescimento de copa da cultivar 'Cornicabra' na Espanha (PEREZ-LOPEZ et al., 2008).

A Tb dos vegetais apresenta diferença entre espécies e entre cultivares dentro da mesma espécie e pode variar em função do estágio de desenvolvimento que a cultura se encontra (LAGO et al., 2009). No caso deste estudo, a Tb foi estimada para o desenvolvimento vegetativo, representado pelo NF. Os valores de $\mathrm{Tb}$ estimados para a Arbequina $\left(10,5^{\circ} \mathrm{C}\right)$ e MGS ASC315 $\left(11,0^{\circ} \mathrm{C}\right)$ foram semelhantes aos valores encontrados para o desenvolvimento vegetativo tanto de culturas perenes, como Eucalyptus grandis $\left(10,0^{\circ} \mathrm{C}\right)$ (MARTINS et al., 2007), como para algumas culturas anuais, como tomate $\left(10,0^{\circ} \mathrm{C}\right)$ (PIVETTA et al., 2007), berinjela $\left(10,0^{\circ} \mathrm{C}\right)$ (MALDANER et al., 2009) e biótipos de arroz vermelho $\left(10,5^{\circ} \mathrm{C}\right)$ (LAGO et al., 2009).

Com os valores de $\mathrm{Tb}$ estimados para a Arbequina e MGS ASC315 obteve-se os valores de filocrono. Valores de $\mathrm{R}^{2}$ acima de 0,8738 entre NF e STa foram obtidos para as duas cultivares nas duas épocas de transplantio, em todas as repetições, indicando que a estimativa do filocrono pelo método da regressão linear é apropriada (XUE et al., 2004; MARTINS et al., 2007). Um exemplo dessa linearidade encontra-se na figura $1 c, d, e, f$.

A análise de variância para a variável filocrono foi significativa apenas para o fator cultivar $(\mathrm{P}<0,05)$, sendo não significativa para o fator época de transplantio $(\mathrm{P}=0,1952)$ e interação entre os fatores $(\mathrm{P}=0,0630)$. Dessa forma, realizou-se a análise apenas para o fator cultivar, e o filocrono médio das 15 repetições obtido para a Arbequina foi de 21,7 ( $\pm 8,4)$, e para a MGS ASC315 foi de $41,6( \pm 10,9){ }^{\circ} \mathrm{C}$ dia $^{-1}$ folha $^{-1}$. Essa diferença entre os valores de filocrono para a Arbequina e MGS ASC315 foi significativa pelo teste Scott Knott (5\%). A Arbequina necessita acumular menor quantidade de energia térmica $\left({ }^{\circ} \mathrm{C}\right.$ dia $^{-1}$ ) que a MGS ASC315 para emitir uma folha. Esse resultado foi coerente, pois se observou no campo que as folhas da Arbequina aparecem antes que as folhas da MGS ASC315.

Para entender o que esses valores de filocrono representam no sentido prático é necessário verificar os valores de STa na fase final de muda (cerca de 20 folhas acumuladas) para cada cultivar. A Arbequina atinge a fase final de muda aos $786,0^{\circ} \mathrm{C} \mathrm{dia}^{-1}$ (E5) e $663,65^{\circ} \mathrm{C} \mathrm{dia}^{-1}$ (E6), enquanto a MGS ASC315 atinge esse mesmo patamar aos $949,6^{\circ} \mathrm{C}$ dia $^{-1}$ (E5) e $1052,6^{\circ} \mathrm{C} \mathrm{dia}{ }^{-1}$ (E6). O que significa uma diferença média de STa de $276,2^{\circ} \mathrm{C}$ dia $^{-1}$, os quais podem representar vários dias do calendário civil, especialmente quando a temperatura do ar é baixa. Na região sul de $\mathrm{MG}$ temperaturas amenas do ar são bastante comuns de ocorrerem no final do outono e durante o inverno.

Informações básicas sobre o desenvolvimento, como a estimativa da $\mathrm{Tb}$ e a determinação do filocrono, em cultivares de oliveira são interessantes para conhecer as cultivares mais adaptadas para as condições climáticas de cultivo e as necessidades da cultura em condições meteorológicas distintas do seu centro de origem. Certamente, esse tipo de informação é fundamental para o planejamento da implantação e do manejo da oliveira no campo.

\section{CONCLUSÃO}

O método do menor quadrado do erro foi eficiente para estimar a temperatura base das duas cultivares de oliveira. Já o desenvolvimento da oliveira foi quantificado apropriadamente pelo filocrono, demonstrando que a Arbequina é mais adaptada as condições climáticas do sul de Minas Gerais do que a MGSASC315.

\section{AGRADECIMENTOS}

Ao Conselho Nacional de Desenvolvimento Científico e Tecnológico (CNPq) pelo apoio financeiro concedido ao segundo autor. À Empresa de Pesquisa Agropecuária de Minas Gerais (EPAMIG) pela infra-estrutura disponibilizada. À Eng. Florestal Priscila Martins Lisboa pelo auxílio na coleta dos dados do experimento.

\section{REFERÊNCIAS}

ACEBEDO, M.M. et al. In vitro germination of embryos for speeding up seedling development in olive breeding programmes. Scientia Horticulturae, v.69, n.3-4, p.207-215, 1997. Disponível em: <http://www.sciencedirect.com/science/article/ pii/s0304423897000046>. Acesso em: $21 \mathrm{dez}$. 2011. doi: http://dx.doi.org/10.1016/S0304-4238(97)00004-6.

ALCALÁ, A.R.; BARRANCO, D. Prediction of flowering time in olive for the Cordoba Olive Collection. HortScience, v.27, n.11, p.1205-1207, 1992. Disponível em: <http:// hortsci.ashspublications.org/content/27/11/1205.full.pdf+html $>$. Acesso em: 3 jan. 2012.

ARNOLD, C.Y. Maximum-minimum temperature as a basis for computing heat units. Americam Society for Horticulture Science, v.76, n.1, p.682-692, 1960. 
ASSUMPÇÃO NETO, A. Plastocrono e filocrono aparentes anual em Araucaria angustifolia (BERT.) O. KTZE., no município de Colombo - PR. 2008. 55f. Dissertação (Mestrado em Agronomia) - Programa de Pós-graduação em Agronomia, Universidade Federal do Paraná. Disponível em: <http://dspace.c3sl.ufpr.br:8080/dspace/bitstream/handle/1884/ 17433/Disserta\%C3\%A7\%C3\%A3o.pdf?sequence=1>. Acesso em: 3 jan. 2012.

AYERZA, R.; SIBBETT, G.S. Thermal adaptability of olive (Olea europaea L.) to the Arid Chaco of Argentina. Agricultural, ecosystems and Environment, v.84, n.3, p.277-285, 2001. Disponível em: <http://www.sciencedirect.com/science/article/pii/ S0167880900002607>. Acesso em: 3 jan. 2012. doi: http:// dx.doi.org/10.1016/S0167-8809(00)00260-7.

DENNEY, J.O. et al. Modeling the thermal adaptability of the olive (Olea europaea L.) in Texas. Agricultural and Forest Meteorology, v.35, n.1-4, p.309-327, 1985. Disponível em: $<$ http://www.sciencedirect.com/science/article/pii/ 0168192385900929>. Acesso em: 19 nov. 2011. doi: http:// dx.doi.org/10.1016/0168-1923(85)90092-9.

GOULAS, V. et al. Phytochemicals in olive-leaf extracts and their antiproliferative activity against cancer and endothelial cells. Molecullar Nutricional \& Food Research, v.53, n.5, p.600-608, 2009. Disponível em: <http://onlinelibrary.wiley.com/ doi/10.1002/mnfr.200800204/abstract>. Acesso em: 6 dez. 2011. doi: http://dx.doi.org/10.1002/mnfr.200800204.

IOC (INTERNATIONAL OLIVE COUNCIL). Acesso em 5 jan. 2012. Online. Disponível em: <http://www.internationaloliveoil.org/ estaticos/view/135-imports-by-selected-markets>.

KOEFENDER, J. et al. Estimativa do filocrono em calêndula. Ciência Rural, v.38, n.5, p.1246-1250, 2008. Disponível em: <http://www.scielo.br/pdf/cr/v38n5/a07v38n5.pdf>. Acesso em: 9 jan. 2012. doi: http://dx.doi.org/10.1590/S010384782008000500007 .

LAGO, I. et al. Estimativa da temperatura base do subperíodo emergência-diferenciação da panícula em arroz cultivado e arroz vermelho. Revista Ceres, v.56, n.3, p.288-295, 2009. Disponível em: <http://www.ceres.ufv.br/CERES/revistas/ V56N003P52509.pdf >. Acesso em: 9 jan. 2012.

LUCAS, D.D.P. et al. Temperatura base para emissão de nós e plastocrono de plantas de melancia. Revista Ciência Agronômica, v.43, n.2, p.288-292, 2012. Disponível em: <http://www.ccarevista.ufc.br/seer/index.php/ccarevista/article/ viewFile/1301/684>. Acesso em: 9 jan. 2012.

MALDANER, I.C. et al. Filocrono, área foliar, e produtividade de frutos de berinjela conduzidas com uma e duas hastes por planta em estufa plástica. Ciência Rural, v.39, n.3, p.671677, 2009. Disponível em: <http://www.scielo.br/pdf/cr/v39n3/ a119cr793.pdf>. Acesso em: 8 jan. 2012. doi: http://dx.doi.org/ 10.1590/S0103-84782009005000013.

MARTINS, F.B. et al. Estimativa da temperatura-base para emissão de folhas e do filocrono em duas espécies de eucalipto na fase de muda. Revista Árvore, v.31, n.3, p.373-381, 2007. Disponível em: <http://www.scielo.br/pdf/rarv/v31n3/02.pdf>. Acesso em: 6 dez. 2011. doi: http://dx.doi.org/10.1590/S010067622007000300002 .
McMASTER, G.S.; WILHELM, W.W. Growing degree-days: one equation, two interpretations. Agricultural and Forest Meteorology, v.87, n.4, p.291-300, 1997. Disponível em: $<$ http://www.sciencedirect.com/science/article/pii/ S0168192397000270>. Acesso em: 6 jan. 2012. doi: http:// dx.doi.org/10.1016/S0168-1923(97)00027-0.

MELO-ABREU, J.P. et al. Modelling olive flowering date using chilling for dormancy release and thermal time, Agricultural and Forest Meteorology, v.125, n.1-2, p.117-127, 2004. Disponível em: <http://www.sciencedirect.com/science/article/ pii/S016819230400070X>. Acesso em: 8 jan. 2012. doi: http:/ /dx.doi.org/10.1016/j.agrformet.2004.02.009.

MORIONDO, M. et al. Effect of agrometeorological parameters on the phenology of pollen emission and production of olive trees (Olea europea L.). Aerobiologia, v.7, n.3, p.225-232, 2001. Disponível em: <http://www.springerlink.com/content/ x3mpq33553370t33/>. Acesso em: 20 jan. 2012. doi: http:// dx.doi.org/10.1023/A:1011893411266.

PÉREZ-LÓPEZ, D. et al. Influence of temperature on the growth and development of olive (Olea europaea L.) trees. Journal of Horticultural Science \& Biotechnology, v.83, n.2, p.171-176, 2008. Disponível em: <http://www.jhortscib.org/ Vol83/83_2/7.htm>. Acesso em: 20 jan. 2012.

PIVETTA, C.R. et al. Emissão e expansão foliar em três genótipos de tomateiro (Lycopersicon esculentum Mill.). Ciência Rural, v.37, n.5, p.1274-1280, 2007. Disponível em: <http://www.scielo.br/pdf/cr/v37n5/a09v37n5.pdf >. Acesso em: 7 dez. 2011. doi: http://dx.doi.org/10.1590/S010384782007000500009 .

ROSA, H.T. et al. Métodos de soma térmica e datas de semeadura na determinação de filocrono de cultivares de trigo. Pesquisa Agropecuária Brasileira, v.44, n.11, p.1374-1382, 2009. Disponível em: <http://www.scielo.br/pdf/pab/v44n11/02.pdf>. Acesso em: 7 dez. 2011. doi: http://dx.doi.org/10.1590/S0100204X2009001100002.

SANZ-CORTÉS, F. et al. Phenological growth stages of olive trees (Olea europaea). Annals of Applied Biology, v.140, n.2, p.151-157, 2002. Disponível em: <http://onlinelibrary.wiley.com/ doi/10.1111/j.1744-7348.2002.tb00167.x/abstract>. Acesso em: 27 jan. 2012. doi: http://dx.doi.org/10.1111/j.17447348.2002.tb00167.x.

SINCLAIR, T.R. et al. Sugarcane leaf area development under field conditions in Florida, USA. Field Crops Research, v.88, n.2-3, p.171-178, 2004. Disponível em: <http://www.sciencedirect.com/ science/article/pii/S0378429003002727>. Acesso em: 20 nov. 2011. doi: http://dx.doi.org/10.1016/j.fcr.2003.12.005.

STRECK, N.A. et al. Estimating the phyllochron in lily (Lilium longiflorum Thumb.). Revista Brasileira de Agrometeorologia, v.12, n.2, p.355-358, 2004.

STRECK, N.A. et al. Estimating leaf appearance and phyllochron in safflower (Carthamus tinctorius L.). Ciência Rural, v.35, n.6, p.1448-1450, 2005. Disponível em: <http://www.scielo.br/ pdf/cr/v35n6/a36v35n6.pdf>. Acesso em: 6 set. 2011. doi: http://dx.doi.org/10.1590/S0103-84782005000600036.

STRECK, N.A. et al. Temperatura base para aparecimento de folhas e filocrono da variedade de milho BRS Missões. Ciência 
Rural, v.39, n.1. p.224-227, 2009. Disponível em: <http:// www.scielo.br/pdf/cr/v39n1/a35v39n1.pdf>. Acesso em: 7 dez. 2011. doi: http://dx.doi.org/10.1590/S0103-84782009000100035.

VIEIRA NETO, J. et al. Desempenho de jardins clonais de oliveira (Olea europaea L.) em cortes sucessivos visando a sua propagação por estaquia. Cerne, v.17, n.1, p.117-122, 2011. Disponível em: <http://www.dcf.ufla.br/cerne/administracao/ publicacoes/m515v17n1o14.pdf>. Acesso em: 8 jan. 2012.

VOLPE, C. A. et al. Influência da soma térmica e da chuva durante o desenvolvimento de laranjas 'Valência' e 'Natal' na relação entre sólidos solúveis e acidez e no índice tecnológico do suco. Revista Brasileira de Fruticultura, v.24, n.2, p.436-441, 2002. Disponível em: <http://www.scielo.br/pdf/ rbf/v24n2/a31v24n2.pdf $>$. Acesso em: 8 jan. 2012. doi: http:/ /dx.doi.org/10.1590/S0100-29452002000200031.

XUE, Q. et al. Predicting leaf appearance in field-grown winter wheat: evaluating linear and non-linear models. Ecological Modelling, v.175, n.3, p.261-270, 2004. Disponível em: <http://www.sciencedirect.com/science/article/pii/ S0304380003004800>. Acesso em: 20 nov. 2011. doi: http:/ /dx.doi.org/10.1016/j.ecolmodel.2003.10.018. 